\title{
COVID-19 Pandemic: The Circus is Over, for the Moment
}

\author{
Philip Morrissey (10
}

Received: 25 May 2020 / Accepted: 3 August 2020

(C) Journal of Bioethical Inquiry Pty Ltd. 2020

\begin{abstract}
This critical essay responds to the COVID-19 pandemic and subsequent lockdown in Victoria from the perspective of a retired Aboriginal academic and reflects on personal responsibility, Indigenous history, and resilience.
\end{abstract}

Keywords Indigenous · Ethics · Ecology $\cdot$ Culture Survival

And the sky opened

And we laid down our armour

And we danced

Naked as they

Baptized in the rain

Of the New World

"Amerigo" (Smith 2012)

At the commencement of Melbourne's April COVID-19 lockdown the Australian Government Department of Health released this statement:

People aged 70 years and over, people aged 65 years and over with chronic medical conditions, people with compromised immune systems, and Aboriginal and Torres Strait Islander people over the age of 50, are at greater risk of more serious illness if they are

P. Morrissey $(\bowtie)$

Box Hill, Australia infected with coronavirus. (Australian Government Department of Health 2020)

So there I was, interpellated as one of those Aboriginals, over fifty years of age. There was something ominous in it, though I had every confidence that the Department of Health injunctive was based on the advice of well-meaning Aboriginal health experts. My disquiet at the statement? I see myself as relatively privileged, in good health, and with the capacity to make any necessary decisions relevant to my health and lifestyle. There was also concern at the increased nuisancing powers given to the Victorian police force, at a time when it had never been in greater disrepute. But at the base of my anxiety were the darker shadows of history - the Aboriginal experience of the intertwined realities of invasion, colonization, and foreign-brought disease. In the words of Wiradjuri poet Jazz Money:

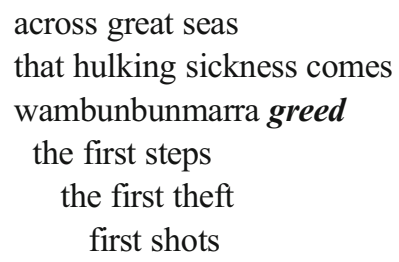

Two novels published in the late twentieth century provide us with specific perspectives on the Aboriginal experience of disease and invasion and the culture that produces them. Eric Wilmot's 1987 historical novel Pemulwuy: The Rainbow Warrior takes as its subject matter conflict between the Eora nation and the British 
invaders between 1788 and 1802. As smallpox (Galgalla) spreads among the Eora people, Pemulwuy, the Aboriginal leader who believes in opposing the British with force, tells the more conciliatory leader Bennelong, that a truce agreed to between the British and Eora can be broken by the British killing the Eora with muskets, bayonets, swords, or deliberately with the release of their "sickness," the "galgalla in a jar" (Wilmot 1994 [1987], 190-191). (The novel itself suggests that the release of the smallpox cultures was accidental rather than deliberate.)

Responding to Pemulwuy's charge, Captain Macarthur, the commander of the Parramatta Stockade, outlines what amounts to a rationalization of germ warfare,

The fact is that civilisation brings with it diseases that primitives simply cannot bear as we can... Their bodies are not resilient. Pemulwuy knows that full well. The rumour of the fatal jar is useful to him. It adds a touch of drama. But in a sense he is right. Disease is our invisible weapon. Our sickness will cut a massive swathe through the native's ranks as we move through this continent, settling it and converting it to useful cultivation. (Wilmot 1994 [1987], 192-193).

Wilmot's point is that both the British and the Eora understand that there is nothing incidental about the galgalla and it is seen as integral to invasion and colonization.

A later novel, Bruce Pascoe's Shark, extends the discussion and identifies the factors that create disease bearing cultures and the disordered psychology of their citizens. The central character, Jim Fox, has an ambivalent, disconnected, relationship with his Aboriginal heritage and in consequence his country. When we encounter Fox he is working as a deckhand in a small Victorian coastal town but he has an international dimension and as a young man fought with the Papuan resistance to the Indonesian invasion and colonization of West Papua. Though mild and self-effacing Fox speaks with trenchant, almost bitter, passion on cultures dependent on wheat, rice, and other grains and the social hierarchies and over-population that result from lowquality, abundant food. He summarizes those cultures in the following manner:

... too many people too close. The rats start to squabble over the crusts. There's got to be space between people. Room to be alone, room to move to another camp, find more fish, more fruit ... No town dwelling civilisation has ever survived more than few hundred years without being run down by the next mob of rats. (Pascoe 1999, 98)

(We should note Pascoe's later (2014) non-fiction work Dark Emu: Black Seeds: Agriculture or Accident argues the contrary thesis.)

Fox goes on:

All I know is what I know. And I know we're going nowhere living in high-rise flats and motor cars. The planet can't support it. And we, people, can't survive it. We're going mad. The worst side of our nature is encouraged by this crowdedness - this anonymous way we live. (Pascoe 1999, 99)

In the absence of direct experience of COVID-19 my perceptions are of hysteria which accompanies the early stages of the pandemic. I'm surprised at the ease with which it is generated and spreads. There is a foreignness about the behaviour but it's also the social glue that for the moment binds an anomic society into a dysfunctional community. Behaviour formerly unthinkable becomes normal for a time. Images of frightened politicians and mass media reports of profiteers, shelf strippers, panicked shoppers, the aged and infirm pushed aside. There are reports of mass deaths and anonymous funerals for the dead in Spain and Italy and the anticipation of the same in Australia. These reports are leavened with tales of individual resilience, generosity, courage, and humour. In all this we witness efficacy of news/entertainment media storytelling, manufacturing reality even as it pretends to do nothing but report it (de Certeau 1986).

Confronted with that pandemonium the affective part of my nature finds respite in First Nations dancers from North America and Canada. The dancers (many of them children and adolescents) post videos of solo dances on a dedicated Facebook page. They often offer their performance for family members, the sick, or those who cannot dance for themselves. In one post, a soldier, cut off from his family, home community, and regalia because of the pandemic, dances in his army uniform; in another, a small girl from Pine Ridge Indian Reservation in full regalia, dances in the snow; another child dancer executes hieratic steps with unwavering concentration. The best dancers, whatever their age, have an integrity and self-possession. The psychic energy that elsewhere 
transforms into hysteria is integrated by the dancer, and by the viewer, into an Indigenous consciousness grounded in tradition and oral history and resolute in the face of the latest contagion.

Aside from that necessary affective engagement, an intellectual and ethical response can be found in the philosophy of Iris Murdoch. Murdoch believes that reason and discernment can provide guidance and personal integrity for the individual and is uncompromising in her belief in the individual as the basis for the creation of a moral subject. Beyond the shared morality of the demos there is the possibility of an ever-deepening understanding of moral concepts in the specific circumstances of an individual life. And in a deepening understanding of what morality is one proceeds "onward into increasing privacy ... and not back towards a genesis in the rulings of an impersonal public language" (Murdoch 2007 [1970], 28). Murdoch asserts that as "moral agents we have to try to see justly, overcome prejudice, to avoid temptation, to control and curb imagination, to direct reflection" (Murdoch 2007 [1970], 39).

The challenge with the above is that Murdoch proposes something that is moral and hence difficultgoing against our natural inclination toward ease and laziness. It is the self that must try and live out these precepts and through discernment and reason give order and meaning to chaos and confusion. And though the concept of a responsible moral subject is implicit in intellectual and religious traditions in the West it may no longer have moorings in a consumer capitalist society.

An alternative means to a resistant privacy in a mass society is indicated by Marcuse. He suggested the aesthetic experience and the private sphere could serve as "bulwarks against a society which administers all dimensions of human existence" (Marcuse 2003, 38). And posthysteria in this time of contagion and quarantine there is an appreciation of the quietness, clean air and bluer skies; one can see further, hear more; affections buried under the commonplaces of everyday life reawaken with surprising intensity; football ovals surrounded by wooded embankments become theatres of space and freedomand a reminder that we are guests on Wurundjeri land, and share it with all manner of animals. Without any regret we see how unnecessary humans are to the rest of creation. In those moments of intense quietness, and empty streets one feels like a ghostly witness to the end of the human world. And what was normal about that world prior to the lockdown? And how long before that infranormality re-establishes itself?

Reflecting on this odd moment I was standing in my garden, enjoying the cold early morning air, when not more than fifty metres away the perfectly executed notes of The Last Post sounded through the darkness. After a minute's silence the echoing notes of a trumpet somewhere in the distance were heard. I realized I had become an unwitting, but not unwilling, participant in the Anzac Day Virtual Commemoration Service when Australians had been asked to stand and observe a minute's silence in their driveways at dawn but I was powerfully reminded, at the same time, of the final scene of Fellini's I Clowns (Fellini 1970). Two clowns perform a poignant duet on trumpets, engaging in a call and response, then meeting in centre ring and playing in unison while exiting a dark and deserted circus.

\section{References}

Australian Government Department of Health. 2020. Coronavirus (COVID-19) advice for older people. Last updated 14 May 2020. https://www.health.gov.au/news/healthalerts/novel-coronavirus-2019-ncov-health-alert/advice-forpeople-at-risk-of-coronavirus-covid-19/coronavirus-covid19-advice-for-older-people. Accessed 10 Apr 2020.

de Certeau, M. 1986. Heterologies: Discourse on the Other. Translated by B. Massumi. Minneapolis \& London: University of Minnesota Press.

Fellini, F. (Writer/Director), and B. Zapponi (Writer). 1970. I Clowns [Film]. Italy: RAI \& Compagnia Leone Cinematografica. .

Marcuse, H. 2003. The aesthetic dimension: Toward a critique of Marxist aesthetics. Boston. Beacon Press.

Money, J. 2019. Gungunga. Runway Journal. Issue 40: Caption. http://runway.org.au/gungunga/. Accessed April 10, 2020.

Murdoch, I. 2007 [1970]. The sovereignty of good. London \& New York: Routledge.

Pascoe, B. 2014. Dark emu: Black seeds: Agriculture or accident. Broome: Magabala Books. 1999. Shark. Broome: Magabala Books.

Smith, P. 2012. "Amerigo.” Banga [studio album]. New Jersey: Columbia Records. https://www.songfacts.com/facts/pattismith/amerigo. Accessed April 10, 2020.

Wilmot, E. 1994 [1987]. Pemulwuy: The Rainbow Warrior. Moorebank: Bantam Books.

Publisher's note Springer Nature remains neutral with regard to jurisdictional claims in published maps and institutional affiliations. 